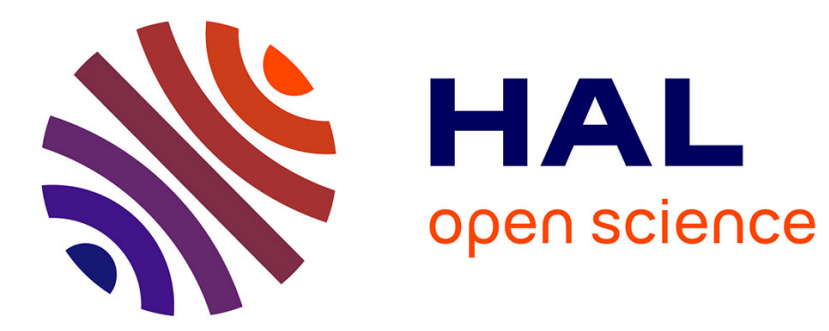

\title{
Paramagnetic point and pair defects in oxide perovskites
} K.A. Müller

\section{To cite this version:}

K.A. Müller. Paramagnetic point and pair defects in oxide perovskites. Journal de Physique, 1981, 42 (4), pp.551-557. 10.1051/jphys:01981004204055100 . jpa-00209041

\section{HAL Id: jpa-00209041 https://hal.science/jpa-00209041}

Submitted on 1 Jan 1981

HAL is a multi-disciplinary open access archive for the deposit and dissemination of scientific research documents, whether they are published or not. The documents may come from teaching and research institutions in France or abroad, or from public or private research centers.
L'archive ouverte pluridisciplinaire HAL, est destinée au dépôt et à la diffusion de documents scientifiques de niveau recherche, publiés ou non, émanant des établissements d'enseignement et de recherche français ou étrangers, des laboratoires publics ou privés. 


\title{
Paramagnetic point and pair defects in oxide perovskites $\left({ }^{*}\right)$
}

\author{
K. A. Müller \\ IBM Zurich Research Laboratory, Säumerstrasse 4, 8803 Rüschlikon, Switzerland
}

(Reçu le 3 septembre 1980, accepté le 22 décembre 1980)

\begin{abstract}
Résumé. - Le but de cet article est de présenter une synthèse des résultats concernant la résonance paramagnétique électronique (RPE) des défauts placés en substitution dans des oxydes doubles $\mathrm{ABO}_{3}$ de structure perovskite. Les sites du réseau et les valences des ions substituants sont considérés dans le paragraphe 2. L'existence des paires métal de transition-vacance d'oxygène, $M e-V_{O}$, et leurs structures atomiques sont analysées dans les paragraphes 3 et 4 . La détermination de la position locale de $\mathrm{Fe}^{3+}$ au site $\mathrm{B}$ dans les cristaux présentant des transitions de phase ferroélectriques est présentée dans le paragraphe 5 tandis que les valeurs anormalement basses du paramètre cubique RPE de $\mathrm{Fe}^{3+}$ sont discutées dans le paragraphe 6 .
\end{abstract}

\begin{abstract}
A review is given of electron paramagnetic resonance (EPR) research of substitutional defects in $\mathrm{ABO}_{3}$ double oxides crystallizing in the perovskite structure. In section 2 , the valency and lattice sites are considered. In section 3, the existence of transition metal-oxygen vacancy pairs, $\mathrm{Me}-\mathrm{V}_{\mathrm{O}}$, is reviewed, and in 4, their atomic structure is analysed. In section 5, the determination of the local position of $\mathrm{Fe}^{3+}$ at $\mathrm{B}$ sites in crystals undergoing ferroelectric phase transitions is presented, and its anomalously low cubic splitting EPR parameter discussed in 6 .
\end{abstract}

1. Introduction. - Electron paramagnetic resonance of transition metal ions in $\mathrm{ABO}_{3}$ compounds has been used over the past 25 years to study a variety of subjects. These studies provided a deeper insight into the resonance phenomenon itself, as was the case for $\mathrm{Fe}^{3+}$ in a cubic crystal field [1], or into the JahnTeller effect [2], and they permitted an investigation of structural [3] and ferroelectric phase transitions [4]. This paper is an attempt to summarize the present knowledge of certain defects, in particular the conditions of their occurrence, and their structure.

2. Valency and lattice sites. - Double oxides $\mathrm{ABO}_{3}$ with perovskite structure are nearly all cubic if heated to sufficiently high temperatures; the cubic lattice constants are observed to be around $4 \AA$. The $\mathrm{A}$ ion, with a radius of $1-1.4 \AA$, is dodecahedrally coordinated by oxygens, and the $B$ ion sits in an oxygen octahedron. Its radius is about half that of the $\mathrm{A}$ ion in order to yield a Goldschmidt tolerance factor of $t=\overline{\mathrm{AO}} / \sqrt{2} \cdot \overline{\mathrm{BO}}$ near unity [5]. Due to these sizes, the transition metal impurities substitute on the B site, and the rare-earth ions on the A sites. Early examples of such EPR studies are $\mathrm{Fe}^{3+}$ on the $\mathrm{B}$ site and $\mathrm{Gd}^{3+}$ on the $\mathrm{A}$ site in $\mathrm{SrTiO}_{3}[1,6]$ and $\mathrm{BaTiO}_{3}[4,6]$. However, in $\mathrm{KTaO}_{3}$

(*) Conférence donnée lors de la Réunion Française de Ferroélectricité, le 19 septembre 1980, à Lyon, France. single crystals grown from $\mathrm{K}_{2} \mathrm{CO}_{3}-\mathrm{Ta}_{2} \mathrm{O}_{5}$ solutions, $\mathrm{Fe}^{3+}$ and $\mathrm{Ni}^{3+}$ ions on $\mathrm{K}^{+}$sites have been observed [7] apart from normal Ta site occupation. $\mathrm{Gd}^{3+}$ on $\mathrm{Ti}$ sites has been reported for ceramic $\mathrm{BaTiO}_{3}$ synthetized with enriched $\mathrm{Ba}$ versus $\mathrm{Ti}$ ratios as well as for reduced and quenched $\mathrm{BaTiO}_{3}$ single crystals [8]. $\mathrm{Ti}^{3+}$ offcentre on $\mathrm{Sr}^{2+}$ sites has been observed in $\mathrm{SrTiO}_{3}$ after neutron irradiation and in one case after reduction [9].

Whereas the rare-earth ions exhibit their known valencies whether they substitute for an A or B site, i.e., $\mathrm{Pr}^{3+}[10], \mathrm{Gd}^{3+} \mathrm{Eu}^{2+}$, etc. [6], this is not at all the case for the $3 \mathrm{~d}$ transition metal ions on octahedral B sites. Table I compares the valencies observed in $\mathrm{SrTiO}_{3}$ with those in $\mathrm{MgO}$ and $\mathrm{CaO}$. In all three compounds, the stability of the transition ions extends over four valencies. Towards the right, the limit of stability is given by electron loss, towards the left, by hole loss energy.

$$
\begin{aligned}
\mathrm{Me}^{+n} & \rightarrow \mathrm{Me}^{n+1}+\mathrm{e} \\
\mathrm{Me}^{+n} & \rightarrow \mathrm{Me}^{n-1}+\mathrm{h} .
\end{aligned}
$$

These boundaries are functions of the electronic deformation and polarization energy $E_{n}$, the electron affinity of the bulk crystal $\chi$, the impurity Jahn-Teller energy $E_{\mathrm{JT}}$ and crystal-field energies $C_{\mathrm{N}}$. For $\mathrm{MgO}$ and $\mathrm{CaO}$ crystals, Stoneham and Sangster [11] accounted for the observed valency span with largescale computing of $E_{\mathrm{n}}$, and assuming $\chi=-1 \mathrm{eV}$. 
Table I. - References for : $\mathrm{SrTiO}_{3}: \mathrm{V}^{4+}[12] ; \mathrm{Cr}^{3+}[13] ; \mathrm{Cr}^{5+}[14] ; \mathrm{Mn}^{2+}[15] ; \mathrm{Mn}^{4+}[16] ; \mathrm{Fe}^{2+}$ by Mössbauer [17]; $\mathrm{Fe}^{3+}[1] ; \mathrm{Fe}^{4+}$ by opt. abs. [18]; $\mathrm{Fe}^{5+}[19] ; \mathrm{Co}^{3+}$ by Mössbauer [17] and inexistence of $\mathrm{EPR}$ [20]; $\mathrm{Ni}^{2+}[21] ; \mathrm{Ni}^{3+}[2],[21] ; \mathrm{Ni}^{4+}[22] ; \mathrm{MgO} / \mathrm{CaO}[11]$.

\begin{tabular}{|c|c|c|c|c|c|c|c|}
\hline \multicolumn{4}{|c|}{$\mathrm{SrTiO}_{3}$} & \multicolumn{4}{|c|}{$\mathrm{MgO} / \mathrm{CaO}$} \\
\hline & & & & $\mathrm{Ti}^{+}$ & & & \\
\hline & $\mathrm{Cr}^{3+}$ & & $\mathrm{Cr}^{5+}$ & $\mathrm{Cr}^{+}$ & $\mathrm{Cr}^{2+}$ & $\mathrm{Cr}^{3+}$ & \\
\hline $\begin{array}{c}\mathrm{Mn}^{2+} \\
{\left[\mathrm{Fe}^{2+}\right]}\end{array}$ & $\begin{array}{c}\mathrm{Fe}^{3+} \\
{\left[\mathrm{Co}^{3+}\right]}\end{array}$ & $\mathrm{Mn}^{\mathrm{Me}^{++}}$ & $\mathrm{Fe}^{5+}$ & $\begin{array}{l}\mathrm{Fe}^{+} \\
\mathrm{Co}^{+}\end{array}$ & $\begin{array}{l}\mathrm{Mn}^{2+} \\
\mathrm{Fe}^{2+} \\
\mathrm{Co}^{2+}\end{array}$ & $\mathrm{Fe}^{3+}$ & $\mathrm{Mn}^{4+}$ \\
\hline $\mathrm{Ni}^{2+}$ & $\mathrm{Ni}^{3+}$ & $\mathrm{Ni}^{4}+$ & & $\mathrm{Ni}^{+}$ & $\mathrm{Ni}^{2+}$ & $\mathrm{Ni}^{3+}$ & \\
\hline
\end{tabular}

For $\mathrm{SrTiO}_{3}$, the valencies are one charge unit higher than in $\mathrm{MgO}$ and $\mathrm{CaO}$ [11]. As it is known from EPR and optical data that the energies $E_{\mathrm{JT}}$ and $C_{\mathrm{N}}$ are nearly equal; this charge difference must result from different $E_{\mathrm{n}}$ and especially $\chi$ values.

In the early experiments, the one unit higher valencies in $\mathrm{SrTiO}_{3}$ allowed for the first time the detection by EPR of a tetravalent 3d ion, namely, $\mathrm{Mn}^{4+}(S=3 / 2)$ [15]. Later, the EPR of the isoelectronic $\mathrm{Fe}^{5+}$ which chemists had usually assumed to be unstable was found. The existence could be proven by measuring the hyperfine field of the ${ }^{57} \mathrm{Fe}$ isotope to be $-201.0 \pm 3 \mathrm{kG}$ within $5 \mathrm{kG}$, the same as observed for the isoelectronic $3 \mathrm{~d}^{3}$ ions $\mathrm{Mn}^{4+}, \mathrm{Cr}^{3+}$, and $\mathrm{V}^{2+}$. Furthermore, it is of interest that the electron-spin $g$ value, $g=2.013$, exceeds that of the free spin despite $\mathrm{Fe}^{5+}$ being an electron centre (see Fig. 1). The reason is that the energies $E_{\mathrm{t}}$ for charge transfer of an electron from an oxygen $\mathrm{p}$ function onto the $\mathrm{Fe}^{5+}$ become lower

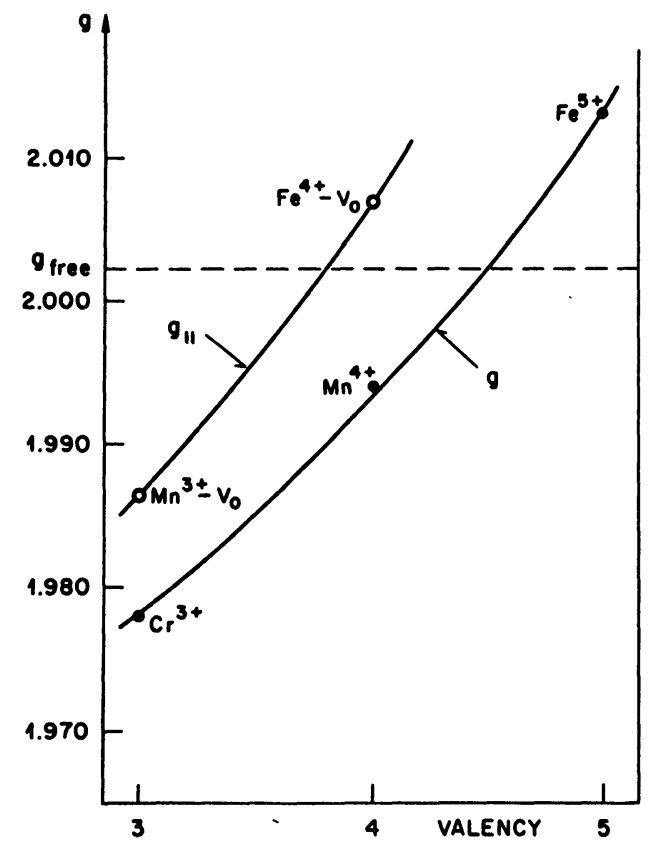

Fig. 1. - The dependence of the $g$ values of the isoelectronic $3 \mathrm{~d}^{3}$ and $3 \mathrm{~d}^{4}-\mathrm{V}_{\mathrm{O}}$ centres as a function of valency from [19] and after [37]. than $\mathrm{Mn}^{4+}$ which in turn are lower than $\mathrm{Cr}^{3+}$. These smaller $E_{\mathrm{t}}$ thus yield a larger positive $g$ shift,

$$
\Delta g=g-g_{\text {free }} \propto 1 / E_{\mathrm{t}} .
$$

On the other hand, the intra-ionic electron excitations become higher, giving less negative shifts in $\Delta g \propto-1 / E_{\mathrm{i}}$ [19].

EPR of $\mathrm{Mn}^{2+}$ in $\mathrm{CaZrO}_{3}$ [23], $\mathrm{BaTiO}_{3}$ and $\mathrm{PbTiO}_{3}$ [24] has been assigned to $B$ sites [15], and an axial $\mathrm{Mn}^{2+}$ centre in $\mathrm{SrTiO}_{3}[25]$ to A sites [15, 26] charge compensated locally by an unknown defect. The EPR of $4 \mathrm{~d}$ transition elements on $\mathrm{B}$ sites such as $\mathrm{Pt}^{3+}$ in $\mathrm{BaTiO}_{3}$ [27], and $\mathrm{Mo}^{5+}$ in $\mathrm{SrTiO}_{3}$ [28] have also been observed, the latter ion exhibiting a dynamic JahnTeller effect as $\mathrm{Ni}^{3+}$ [2].

3. Me-V $\mathrm{V}_{\mathrm{O}}$ pairs. - In cubic $\mathrm{SrTiO}_{3}$ doped with $\mathrm{Fe}$, strong axial EPR spectra between $g_{z}=g_{\|} \simeq 2$ and $g_{\perp} \simeq 6$ occurred. Their $z$ axes were along mutual perpendicular [100], [010] and [001] directions and could be accounted for by $|\Delta M|=1$ transitions between $\pm 1 / 2$ levels resulting from a large axial $D$ splitting of the $S=5 / 2$ state, $D\left(S_{z}^{2}-(1 / 3) S(S+1)\right)$ with $D \simeq 1.4 \mathrm{~cm}^{-1}$ [29]. They were ascribed to $\mathrm{Fe}^{3+}$ ions next to an oxygen vacancy termed $V_{0}$ (located along [100], etc.). Therefore the pair-centre notation $\mathrm{Fe}^{3+}-\mathrm{V}_{\mathrm{O}}$ was introduced. This centre was also found in $\mathrm{KTaO}_{3}$ and $\mathrm{PbTiO}_{3}$ with almost the same $D$ splittings [7, 30], and in $\mathrm{BaTiO}_{3}[31]$. The $\mathrm{Fe}^{3+}-\mathrm{V}_{\mathrm{O}}$ centre was important for the analysis of critical phenomena in the structural phase transition of $\mathrm{SrTiO}_{3}$. The latter involves temperature-dependent alternate rotations $\varphi(T)$ of oxygen octahedra around the $\langle 100\rangle$ axes. The $\mathrm{Fe}^{3+}-\mathrm{V}_{\mathrm{O}}$ centre rotation $\bar{\varphi}(T)$ is 1.6 times smaller than the intrinsic one, but proportional to the intrinsic $\varphi(T)$ near $T_{\mathrm{c}}$, and could be determined with high precision [32].

Since then, the same kind of transition metal ionoxygen vacancy centre has also been observed for other ions and different valencies: $\mathrm{Co}^{2+}-\mathrm{V}_{\mathrm{O}}$ has been reported by Hannon in $\mathrm{KTaO}_{3}$ [33] and in $\mathrm{SrTiO}_{3}$ by Faughnan [34]. The high spin $3 \mathrm{~d}^{7}$ ion $\mathrm{Co}^{2+}\left(\mathrm{t}_{2 \mathrm{~g}}\right)^{4}\left(\mathrm{e}_{\mathrm{g}}\right)^{3}$ yields the $g$ values $g_{\|}=2.061<g_{\perp}=4.933$. The isoelectronic $3 \mathrm{~d}^{7}, \mathrm{Fe}^{1+}-\mathrm{V}_{\mathrm{O}}$ centre has been reported 
by Berney et al. [35] most recently in strongly reduced and thermally quenched $\mathrm{SrTiO}_{3}$ after exposing the samples to subband gap light at low temperatures. The measured $g$ values correspond to those observed in the $\mathrm{Co}^{2}-\mathrm{V}_{\mathrm{o}}$ centre $: g_{\|}=1.999<g_{\perp}=4.116$. The other isoelectronic $3 \mathrm{~d}^{7}$ centre, $\mathrm{Ni}^{3+}-\mathrm{V}_{\mathrm{O}}$ in $\mathrm{SrTiO}_{3}$ has low spin configuration $\left(\mathrm{t}_{2 \mathrm{~g}}\right)^{6} \mathrm{~d}_{3 z^{2}-r^{2}}$. The $z$ axis points towards the positively charged vacancy with $g_{\|}=g_{z}=2.029<g_{\perp}=2.352$ [36]. Upon illumination with visible light, a new and thermally unstable Ni centre is observed with $g_{\|}=2.375>g_{\perp}=2.084$. The angle of rotation $\bar{\varphi}(T)$ of the octahedra is the same as that of the stable $\mathrm{Ni}^{3+}-\mathrm{V}_{\mathrm{O}}$ and the $\mathrm{Fe}^{3+}-\mathrm{V}_{\mathrm{O}}$ centres, and was thus assigned to $\mathrm{a} \mathrm{Ni}^{3+}-\mathrm{V}_{\mathrm{O}}$ centre which has trapped two electrons near the $V_{0}$ with antiparallel spins $\left(\mathrm{Ni}^{3+}-\mathrm{V}_{\mathrm{O}}-2 \mathrm{e}\right)$. The unpaired $\mathrm{e}_{\mathrm{g}}$ electron of the $\mathrm{Ni}^{3+}-\mathrm{V}_{\mathrm{O}}-2 \mathrm{e}$ is in $\mathrm{a}_{x^{2}-y^{2}}$ orbit, i.e., configuration $\left(t_{2 g}\right)^{6} d_{x^{2}-y^{2}}$. The average $g$ value is nearly the same as that of the six-fold coordinated $\mathrm{Ni}^{3+}$. The two trapped electrons are thus delocalized from the $\mathrm{Ni} \mathrm{d}_{3 z^{2}-r^{2}}$ orbitals - which would otherwise form a $\mathrm{Ni}^{1+}\left(\mathrm{d}_{3 z^{2}-r^{2}}\right)^{2} \mathrm{~d}_{x^{2}-y^{2}}$ state - onto the $\mathrm{Ti}^{4+}$ ion on the other side of the oxygen vacancy $\mathrm{V}_{\mathrm{O}}$ along the $z$ axis. This may also be the case for the $\mathrm{Fe}^{1+}-\mathrm{V}_{\mathrm{O}}$ centre mentioned above.

Well-oxidized $\mathrm{Mn}$-doped $\mathrm{SrTiO}_{3}$ exhibits only EPR of $\mathrm{Mn}^{4+}$ substituting for $\mathrm{Ti}^{4+}$. The reduced crystals, however, indicate cubic $\mathrm{Mn}^{2+}$ on $\mathrm{Ti}^{4+}$ sites, and two strong axial spectra along general $\langle .100\rangle$ crystallographic directions [15]. One of them has effective $g$ values of $g_{\|} \simeq 2.00, g_{\perp}^{\text {eff }} \simeq 5.9$, and the other $g_{\|}^{\text {eff }} \simeq 8, g_{\perp}<0.4$. The former spectrum is due to the $\mathrm{Mn}^{2+}-\mathrm{V}_{\mathrm{O}}$ centre with $S=5 / 2$, isoelectronic to $\mathrm{Fe}^{3+}-\mathrm{V}_{\mathrm{O}}$, and an axial splitting of $D=0.54 \mathrm{~cm}^{-1}$. The second centre is quite interesting in its electronic structure. Analysis of this spectrum showed it to be due to a $\mathrm{Mn}^{3+}-\mathrm{V}_{\mathrm{O}}$ pair. Its orbital wave function is quenched by the strong tetrahedral field into a $\mathrm{B}_{2}\left(X^{2}-Y^{2}\right)$ orbital; its spin is $S=2$, and the large negative $D$ spin splitting $|D| \gg h v$ allows EPR observation between the $|2\rangle,|-2\rangle, M_{S}$ ground states. The resonance field varies as

$$
H_{\mathrm{r}}=\left[(h v)^{2}-a^{2}\right] / 4 g_{\|} \beta \cos \theta,
$$

and the hyperfine splitting as $A / 4 g_{\|} \beta \cos \theta$. Here $\theta$ is the angle between $\mathrm{a}\langle 100\rangle$ direction and the external magnetic field, $g_{\|}^{\text {eff }}=4 g_{\|}, a$ is the cubic crystalline splitting, and $A$ the hyperfine interaction constant.

The iron pair-centre, $\mathrm{Fe}^{4+}-\mathrm{V}_{\mathrm{O}}$, isoelectronic to the $\mathrm{Mn}^{3+}-\mathrm{V}_{\mathrm{O}}$, with high spin $S=2$, was observed shortly after the latter [37]. Its net charge is $+2 e$ and it can be observed in $\mathrm{SrTiO}_{3}$ charge compensated with $\mathrm{Mg}^{2+}$, and $\mathrm{Al}^{3+}$ at $\mathrm{Ti}^{4+}$ sites. The existence of the $\mathrm{Fe}^{4+}-\mathrm{V}_{\mathrm{O}}$ had been postulated by Morin and Oliver [38].

In figure 2, the angular dependence of EPR lines due to the $\mathrm{Fe}^{3+}-\mathrm{V}_{\mathrm{O}}$ and $\mathrm{Fe}^{4+}-\mathrm{V}_{\mathrm{O}}$ centres is shown for $77 \mathrm{~K}$, i.e. below the $105 \mathrm{~K}$ structural phase transition of $\mathrm{SrTiO}_{3}$. The rotation angles $\bar{\varphi}(T)$ of the two centres are the same. Note that for $\mathrm{Fe}^{4+}-\mathrm{V}_{\mathrm{O}}$ pairs, an angleindependent line, i.e. the "perpendicular spectrum » is not observed. According to figure 1 , the $g_{\|}$values of the $\mathrm{Mn}^{3+}-\mathrm{V}_{\mathrm{O}}$ and $\mathrm{Fe}^{4+}-\mathrm{V}_{\mathrm{O}}$ centres exhibit the same upward trend with increasing valency as is observed in the $\mathrm{Cr}^{3+}, \mathrm{Mn}^{4+}, \mathrm{Fe}^{5+}$ sequence. The reasons are the same as mentioned at the end of section 2, namely, a decrease of the transfer energies with increasing valency. These charge-transfer energies have been determined by the EPR conversion-rate technique. These investigations have been reviewed elsewhere [39].

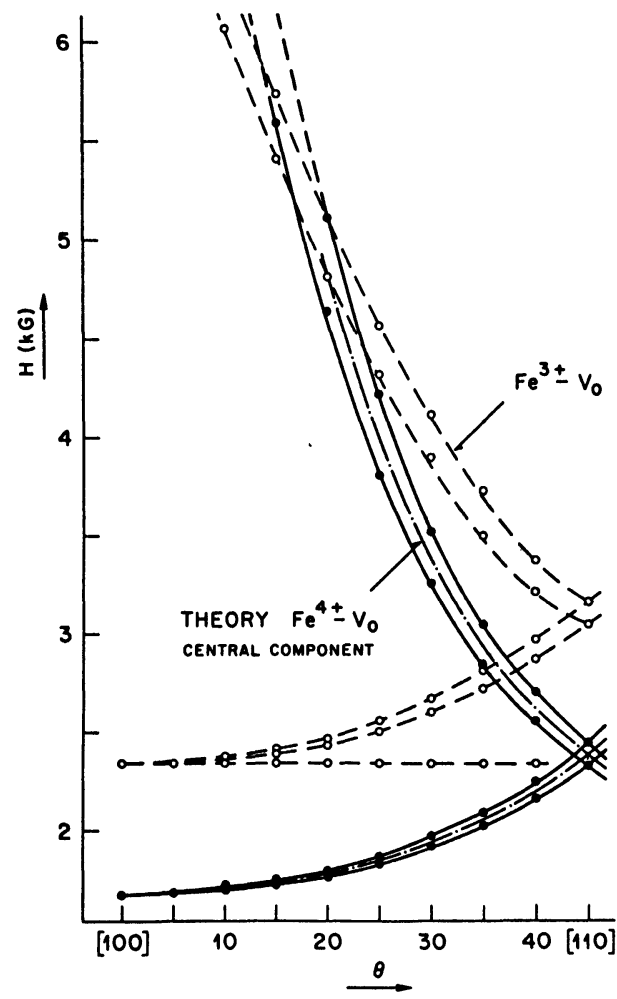

Fig. 2. - Angular dependence of the ESR of $\mathrm{Fe}^{4+}-\mathrm{V}_{\mathrm{O}}$ and $\mathrm{Fe}^{3+}$. $\mathrm{V}_{\mathrm{O}}$ for $H$ in a [100] plane at $\sim 19.5 \mathrm{GHz}$ and $4.2 \mathrm{~K}$ from [37].

In $\mathrm{SrTiO}_{3}$ reduced at high temperatures and then quenched, another axial centre with even spin $S$ has been seen [35]. Assuming $S=2$, an axial splitting parameter $D=9.58 \mathrm{~cm}^{-1}$ was deduced. As the rotation angle $\bar{\varphi}=1.0^{\circ}$ at $77 \mathrm{~K}$, it has been assigned to a $\mathrm{Fe}^{2+}-\mathrm{V}_{\mathrm{O}}$ pair, which upon low-temperature illumination yields the $\mathrm{Fe}^{1+}-\mathrm{V}_{\mathrm{O}}$ centre. Another $\mathrm{Fe}^{3+}$ spectrum of orthorhombic symmetry was also observed [35].

More recently, the neutral $\mathrm{Ti}^{3+}-\mathrm{V}_{\mathrm{O}}$ centre has been reported in Ti-doped $\mathrm{KTaO}_{3}$ [40] with :

$g_{\|}=1.997>g_{\perp}=1.904$. A centre with $g_{\|}=$ $1.932>g_{\perp}=1.914$ in flux-grown $\mathrm{BaTiO}_{3}[41]$ doped with $\mathrm{La}$ was reassigned to a $\mathrm{La}^{3+}-\mathrm{V}_{\mathrm{O}^{-}}-\mathrm{Ti}^{3+}$ 
complex [36] and in $\mathrm{K}^{+}$-doped $\mathrm{BaTiO}_{3}$ [41] to a $\mathrm{Ba}^{2+}-\mathrm{V}_{\mathrm{O}^{-}} \mathrm{Ti}^{3+}[36]$ array. Electron spin resonance results due to holes trapped at oxygen ions and other defects have been reported, but are not related to $\mathrm{Me}-\mathrm{V}_{\mathrm{o}}$ pairs.

4. Structure of the $\mathrm{Fe}^{3+}-\mathrm{V}_{\mathrm{O}}$ and $\mathrm{Mn}^{2+}-\mathrm{V}_{\mathrm{O}}$ pairs. The $\mathrm{Fe}^{3+}$ and $\mathrm{Mn}^{2+}$ ions have a half-filled $3 \mathrm{~d}$ shell, i.e., their configuration is $3 \mathrm{~d}^{5}$, and thus the orbital angular momentum $L$ is zero and their electronic spin $S=5 \times 1 / 2=5 / 2$. For these ions, the spin-Hamiltonian parameter $D$ in the axial field of the $V_{0}$ is quite large, namely of the order of a wave number as reviewed in section 3. For reasons beyond the scope of this paper, $D$ is determined by more than $70 \%$ by the next-neighbour ligand positions. Thus, a missing ligand obviously has a drastic effect. If this is the case (which may not apply to less covalently bound ions, i.e., rare-earth ions such as $\mathrm{Gd}^{3+}$ ), the Newman model involving a superposition of individual nearest-neighbour oxygen contributions yields the parameters $b_{2}^{m}$ with good accuracy [42]. Referring the position of the ligand centres to that of $\mathrm{Fe}^{3+}$ by means of polar coordinates $R_{i}, \theta_{i}, \varphi_{i}$ one obtains

$$
b_{2}^{m}=\bar{b}_{2}\left(R_{0}\right) \sum_{i=1}^{N}\left(\frac{R_{0}}{R_{i}}\right)^{t_{2}} K_{2}^{m}\left(\theta_{i}, \varphi_{i}\right)
$$

with

$$
\begin{aligned}
K_{2}^{0}(\theta) & =1 / 2\left(3 \cos ^{2} \theta-1\right) \\
K_{2}^{2}(\theta, \varphi) & =3 / 2 \sin ^{2} \theta \cos 2 \varphi
\end{aligned}
$$

In equation (1), $R_{0}$ is a reference distance for the intrinsic parameter $\bar{b}_{2}\left(R_{0}\right)$. For $\mathrm{Fe}^{3+}$,

$$
b_{2}(2.101 \AA)=-0.412(25) \mathrm{cm}^{-1},
$$

and the intrinsic exponent $t_{2}=8 \pm 1$ of the model was determined for oxygen ligands using uniaxialstrain EPR data of $\mathrm{Fe}^{3+}$ in $\mathrm{MgO}$, and similar data for $\mathrm{Mn}^{2+}$ [26].

Recently, Siegel and Müller [26] gained information on the $\mathrm{Fe}^{3+}-\mathrm{V}_{\mathrm{O}}$ and $\mathrm{Mn}^{2+}-\mathrm{V}_{\mathrm{O}}$ pair-centre structure using the above model. To compare the different compounds, the quantity $b_{2}^{0} / \bar{b}_{2}(d)$ was used. Here, $b_{2}^{0} \equiv D$ is the measured spin-Hamiltonian parameter, and $\bar{b}_{2}(d)$ the intrinsic parameter for $\mathrm{Fe}^{3+}$ and $\mathrm{Mn}^{2+}$, respectively, and the oxygen ligands at undistorted distance $d$. It was found that for $\mathrm{Fe}^{3+}-\mathrm{V}_{\mathrm{o}}$ pair-centres in $\mathrm{SrTiO}_{3}$ [32], $\mathrm{KTaO}_{3}$, and $\mathrm{PbTiO}_{3}$ [30] as well as $\mathrm{Mn}^{2+}-\mathrm{V}_{\mathrm{O}}$ in $\mathrm{SrTiO}_{3}[15]$, the ratio $b_{2}^{0} / \bar{b}_{2}(d)$ was -2 near $d=2 \AA$. These values were explained with the following model as shown in figure $3:$ i) The $\mathrm{Fe}^{3+}$ or $\mathrm{Mn}^{2+}$ ion can move a distance $\Delta \cdot d$ along the direction of the $\mathrm{C}_{4 \mathrm{v}}$ symmetry axis of the pair-centre; ii) a contraction $(1-c) d$ of the four planar oxygens perpendicular to the $\mathrm{Me}-\mathrm{V}_{\mathrm{O}}$ axis can occur. It is seen that a broad minimum of -1.4 for $b_{2}^{0} / \bar{b}_{2}(d)$ results
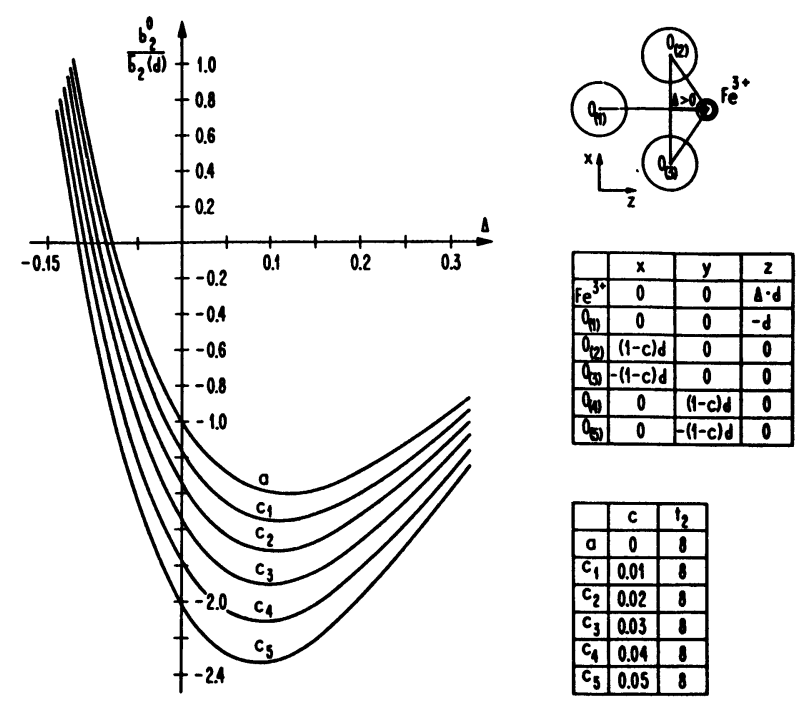

Fig. 3. - Local environment, coordination of the ions, and the prediction of $b_{2}^{0} / \bar{b}_{2}(d)$ for an Me- $\mathrm{V}_{\mathrm{o}}$ centre with different contractions of the four planar oxygen ions from [26].

for $c=0$. When the cation moves towards the vacancy, i.e., $\Delta>0$, more negative values near -2 are obtained for $c \neq 0$. With a $4 \%$ contraction $(c=0.04)$, a minimum of -2.1 at $\Delta_{\min }=0.09$ is reached. Here, $\Delta=0.09$ means a displacement of $0.18 \AA$ towards the vacancy for $d=0.5 a=2 \AA$. For this curve, the values are -2 to -2.1 in the range from $\Delta=$ $0.4(0.08 \AA)$ to $\Delta=0.15(0.3 \AA)$. It is therefore understandable that in compounds where the $\mathrm{Fe}^{3+}$ and $\mathrm{Mn}^{2+}$ movements differ, approximately the same values of $b_{2}^{0} / \bar{b}_{2}(d)$ are reached. The $4 \%$ contraction agrees well with the reduction of the ionic radius of the $\mathrm{Fe}^{3+}$ ion by changing the coordination number from 6 to 5 as listed by Megaw [5]. When the $\mathrm{Fe}$ ions move towards the oxygen vacancy [26], there is a reduction in the rotation angle $\bar{\varphi}$ of the $\mathrm{Fe}^{3+}-\mathrm{V}_{\mathrm{O}}$ centre as compared to the intrinsic angle $\varphi$, below $T_{\mathrm{c}}$. As identical rotation angles have been reported $[35,37]$ for the $\mathrm{Fe}^{4+}-\mathrm{V}_{\mathrm{O}}, \mathrm{Fe}^{3+}-\mathrm{V}_{\mathrm{O}}$ and $\mathrm{Fe}^{2+}-\mathrm{V}_{\mathrm{O}}$ pair-centres, the geometry must be the same. This shows that Coulomb interaction does not play an important role for the centres, as in one case the iron is nominally tetravalent and in the others trivalent and divalent. It follows that the core repulsion is dominant, forcing the metal ion towards the vacancy $V_{0}$.

\section{Local position of $\mathrm{Fe}^{3+}$ in ferroelectric perovskites.} - The most thoroughly investigated ferroelectric crystal in this category is $\mathrm{BaTiO}_{3}$. The ferroelectric phase transition results from the Ti sublattice and the highly polarizable oxygens moving towards each other. The first complete study of $\mathrm{Fe}^{3+}$ in the tetragonal phase was carried out by Hornig, Rempel and Weaver [4]. The $\mathrm{Fe}^{3+}$ substitutes for the $\mathrm{Ti}^{4+}$ on the octahedral 
Table II. - EPR parameters of $\mathrm{Fe}^{3+}$ in four phases of $\mathrm{BaTiO}_{3}$.

\begin{tabular}{|c|c|c|c|c|c|c|c|}
\hline $\begin{array}{c}\text { Crystal } \\
\text { structure } \\
-\end{array}$ & Temperature & Refs. & $\underline{a}\left(\mathrm{~cm}^{-1}\right)$ & $b_{2}^{0}\left(\mathrm{~cm}^{-1}\right)$ & $\begin{array}{c}z \text { axis } \\
\text { direction } \\
-\end{array}$ & Refs. & $\begin{array}{c}\text { Centred Fe } \mathrm{Fe}^{3+} \\
\text { computed } b_{2}^{0}\left(\mathrm{~cm}^{-1}\right)\end{array}$ \\
\hline Cubic & $160^{\circ} \mathrm{C}$ & [4] & +0.0102 & 0 & - & & \\
\hline Tetragonal & $27^{\circ} \mathrm{C}$ & [4] & +0.0091 & +0.0929 & $\langle 100\rangle$ & [47] & +0.105 \\
\hline Orthorhombic & $-60^{\circ} \mathrm{C}$ & [43] & +0.0094 & -0.064 & $\langle 001\rangle \perp \mathrm{P}$ & [47] & -0.057 \\
\hline Rhombohedral & $-196^{\circ} \mathrm{C}$ & [44] & +0.0115 & -0.0023 & $\langle 111\rangle \| \mathrm{P}$ & [47] & $-0.0086 \pm 0.0022$ \\
\hline
\end{tabular}

site, and exhibits a cubic spectrum. Below the cubic $(\mathrm{Pm} 3 \mathrm{~m})$ to tetragonal $(\mathrm{P} 4 \mathrm{~mm})$ ferroelectric transition at about $120^{\circ} \mathrm{C}$, an axial term, with splitting constant $D$, along the $\{001\}$ tetragonal domain axes, had to be added to account for the data. Rimai and De Mars [6] related $D$ to the polarization $P$ and obtained $D=1.6 P^{2}$ if $P$ is measured in $\mu \mathrm{C} / \mathrm{cm}^{2}$ and $D$ in units of $10^{-4} \mathrm{~cm}^{-1}$. These authors also doped the crystals with $\mathrm{Gd}^{3+}$ $(S=7 / 2)$ replacing a $\mathrm{Ba}^{2+}$ ion. The $\mathrm{Gd}^{3+} D$ parameter also varies proportionally to $P^{2}(T)$ [6].

Subsequent studies by Sakudo [43] and Sakudo and Unoki [44] extended the investigations to the orthorhombic Amm2 and rhombohedral R3m phases of $\mathrm{BaTiO}_{3}$. These results are summarized in the fifth column of table II, which presents a number of remarkable facts : i) The cubic-splitting constant $a \simeq 0.01 \mathrm{~cm}^{-1}$ does not vary more than $10 \%$ across the phase changes. This indicates that the $\mathrm{Fe}^{3+}$ sees the same oxygen octahedral environment. ii) Of great importance, the axial $D \equiv b_{2}^{0}$ parameter changes sign on going from the tetrahedral to the orthorhombic phases and no orthorhombic term

$$
E\left(S_{x}^{2}-S_{y}^{2}\right)=\frac{1}{3} b_{2}^{2} O_{2}^{2}
$$

appears. The $z$ axis of the $O_{2}^{0}$ term is parallel [100] and lies perpendicular to the polarization axis [011]. iii) The axial $D$ term in the rhombohedral phase is parallel to the polarization $(P \|[111])$ but it is one to two orders of magnitude smaller than in the tetragonal and orthorhombic phases, although the polarization is of the same order in all polar phases [45]. Later, Takeda reported on his $\mathrm{Gd}^{3+}$ studies in the lower two phases of $\mathrm{BaTiO}_{3}$ [46]. In contrast to the $\mathrm{Fe}^{3+}$ results, he found axial $\left|b_{2}^{0}\right|$ terms directed along $\langle 100\rangle$ and $\langle 111\rangle$ axes of almost the same magnitude, 267 and $340 \times 10^{-4} \mathrm{~cm}^{-1}$, respectively, as compared to $294 \times 10^{-4} \mathrm{~cm}^{-1}$ in the tetragonal phase. These splittings are thus perfectly normal in their magnitude as compared to the polarizations observed in the three phases, and their axes are parallel to the polarization vectors. Takeda computed the field gradients for $\mathrm{Gd}^{3+}$ resulting from the neighbour oxygen positions including their polarization, the same as Sakudo [43] for $\mathrm{Fe}^{3+}$, the contributions from the $\mathrm{Ti}^{4+}$ being small. Takeda obtained reasonable agreement in assuming oxygen polarizations parallel to $\langle 110\rangle$ and $\langle 111\rangle$, whereas Sakudo had to assume oxygen polarizations parallel to $\langle 100\rangle$ directions in the low symmetry phases. Due to this discrepancy, Siegel and Müller [47] most recently used the Newman superposition model for $\mathrm{Fe}^{3+}$ in $\mathrm{BaTiO}_{3}$ to account for the experimental $\mathrm{Fe}^{3+} b_{2}^{m}$ data of table II, i.e., they neglected the direct influence of the polarization of the oxygens, and took only their position into account, and of greatest importance, they relaxed the assumption of earlier researchers, that the $\mathrm{Fe}^{3+}$ has the same lattice coordinates as the $\mathrm{Ti}^{4+}$. In one of their models, they allowed the $\mathrm{Fe}^{3+}$ to move freely along the polarization axes by an amount $\Delta \cdot d$. Their investigation gave conclusive evidence that the $\mathrm{Fe}^{3+}$ participates by less than an order of magnitude in the collective off-centre $\mathrm{Ti}^{4+}$ motion, i.e., it remains at the approximate centre of the octahedron. In the last column of table II, computed values of $b_{2}^{0}$ are listed using equation (1) without adjustable parameters. They were obtained with the intrinsic constants $\bar{b}_{2}\left(R_{0}\right)$ and $t_{2}$ given in section 4 and assuming a centred $\mathrm{Fe}^{3+}$ in the octahedron using the intrinsic positions of the oxygens as determined from refined X-ray scattering analysis. Note, that with this analysis, a near-axial term with $z \perp P$ in the orthorhombic phase, i.e., $b_{2}^{2} \ll b_{2}^{0}$ was obtained. In the rhombohedral $\mathrm{BaTiO}_{3}$ phase, the oxygens are located on an almost undistorted octahedron. As the $\mathrm{Fe}^{3+}$ is very near its centre, the axial $b_{2}^{0}$ term almost vanishes. The success of this analysis implies that the polarization fields can be neglected as compared to the effect of the nearest-neighbour positions. It justifies an assumption of Wemple [48] in deriving the $D=1.4 P^{2}$ formula from polarization-induced strain only, neglect-

Table III. - EPR parameters of $\mathrm{Fe}^{3+}$ in $\mathrm{PbTiO}_{3}$ and $\mathrm{KNbO}_{3}$.

\begin{tabular}{|c|c|c|c|c|c|c|c|}
\hline Crystal & Structure & Temperature & Refs. & $b_{2}^{0}\left(\mathrm{~cm}^{-1}\right)$ & $\begin{array}{c}z \text { axis } \\
\text { direction }\end{array}$ & Refs. & $\begin{array}{l}\text { Centred } \mathrm{Fe}^{3+} \\
\text { computed } b_{2}^{0}\end{array}$ \\
\hline $\mathrm{PbTiO}_{3}$ & tetragonal & $300 \mathrm{~K}$ & [49] & $+0.53 \pm 0.02$ & $\langle 100\rangle \| P$ & [47] & $+0.58 \pm 0.14$ \\
\hline $\mathrm{KNbO}_{3}$ & orthorhombic & $300 \mathrm{~K}$ & [50] & $\begin{aligned}|0.18 \pm 0.001| & \pm 0.17 \\
\left|b_{2}^{2} / D\right| & =0.17\end{aligned}$ & $\langle 001\rangle \perp \mathrm{P}$ & $\begin{array}{l}{[47]} \\
{[47]}\end{array}$ & $\begin{array}{c}-0.15 \pm 0.04 \\
\left|b_{2}^{2} / D\right|=0.12 \pm 0.1\end{array}$ \\
\hline
\end{tabular}


ing the direct polarization effect on the centred $\mathrm{Fe}^{3+}$ ion.

Analog results to $\mathrm{BaTiO}_{3}$ were also obtained for $\mathrm{Fe}^{3+}$ in $\mathrm{PbTiO}_{3}$ and $\mathrm{KNbO}_{3}$ [47]. Table III compiles the known experimental $\mathrm{Fe}^{3+}$ EPR parameters of $\mathrm{PbTiO}_{3}$ in the tetragonal [49] and $\mathrm{KNbO}_{3}$ in the orthorhombic phases [50], and compares them to the computed values assuming the $\mathrm{Fe}^{3+}$ to be at the centre of the oxygen octahedron. The agreement is again very satisfactory.

The reduced $\mathrm{Fe}^{3+}$ participation in the collective $\mathrm{Ti}^{4+}$ motion implies that on doping, the transition temperature $T_{\mathrm{c}}$ of $\mathrm{BaTiO}_{3}$ must be strongly reduced. This property was indeed found : $1 \%$ doping reduced $T_{\mathrm{c}}$ by $15 \mathrm{~K}$ [51]; the effect of creating $\mathrm{V}_{\mathrm{o}}$ 's, which also reduce $T_{c}$, has been subtracted [52].

The $\mathrm{Fe}^{3+}$ contains five $3 \mathrm{~d}$ electrons $\left(3 \mathrm{~d}^{5}\right)$ in antior non-bonding orbitals. They impede bonding of the oxygen p electrons with the empty $3 \mathrm{~d}$ orbitals, possible in $\mathrm{Ti}^{4+}\left(3 \mathrm{~d}^{0}\right)$ or $\mathrm{Nb}^{4+}\left(4 \mathrm{~d}^{0}\right)$. This points to the very origin of displacive ferroelectricity which is mainly found in oxides containing ions with empty d orbitals. The size and charge of an ion are also important. $\mathrm{Zr}^{4+}$ has an empty $4 \mathrm{~d}^{0}$ orbital like $\mathrm{Nb}^{5+}$ but upon doping into $\mathrm{BaTiO}_{3}$ suppresses $T_{\mathrm{c}}$ because its size $0.72 \AA$ is $0.12 \AA$ larger than that of $\mathrm{Ti}^{4+}$. However, it depresses $T_{\mathrm{c}}$ less than $\mathrm{Sn}^{4+}$ [45] with a radius of only $0.69 \AA$ but a full $4 \mathrm{~d}^{10}$ shell [5]. This shows that for $\mathrm{Zr}^{4+}$, the empty $4 \mathrm{~d}$ shell, which is favourable to ferroelectricity, counteracts the suppressive effect of the large size. We can interpret recent doping experiments of $\mathrm{BaTiO}_{3}$ by Hagemann and Ihrig [52] in the same manner : $\mathrm{Zn}^{2+}$ doping depresses $T_{\mathrm{c}}$ by $15 \mathrm{~K} /$ mol. \%, whereas $\mathrm{Ni}^{2+}$ doping lowers $T_{\mathrm{c}}$ by $30 \mathrm{~K} /$ mol. $\%$. The radius of the former ion is larger, being $0.75 \AA$, the latter only $0.69 \AA$, thus, $\mathrm{Ni}^{2+}$ should depress $T_{\mathrm{c}}$ less if it depended only on the effect of size and creation of $V_{o}$ 's. In our opinion, the enhanced depression observed with $\mathrm{Ni}^{2+}$ results from its almost full $3 \mathrm{~d}$ shell with configuration $3 \mathrm{~d}^{8}$. The $\mathrm{Ga}^{3+}$ and $\mathrm{Fe}^{3+}$ doping experiments of reference [52] can be discussed in a similar manner.

6. The EPR parameter $a$ in $\mathrm{BaTiO}_{3}$ and $\mathrm{KNbO}_{3}$. The $\underline{a}$ parameters shown in table II are about a factor 2.5 smaller than those measured in normal cubic oxides with the same cation-anion distance. This fact and its possible implication remained unnoticed

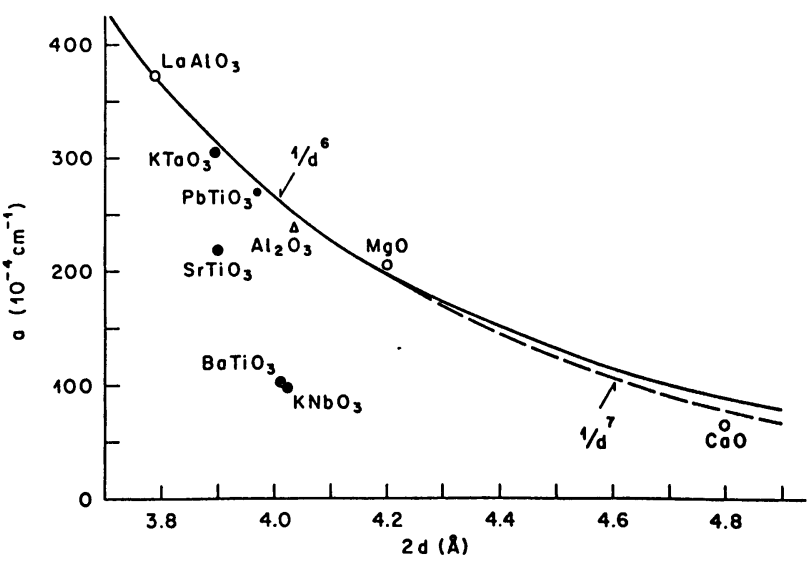

Fig. 4. - EPR cubic splitting parameter $\underline{a}$ of $\mathrm{Fe}^{3+}$ at octahedral sites in oxides as a function of average double cation-anion lattice distance $2 d$. The symbols $\mathrm{O}$, $\bigcirc$ refer to cubic oxide sites without and with ferroelectric soft modes, respectively; $\Delta$ to trigonally distorted octahedral sites in an oxide without a seft mode (from [53]).

for several years. In $\mathrm{BaTiO}_{3}$, the soft ferroelectric mode is overdamped and anisotropic in the cubic phase as in $\mathrm{KNbO}_{3}$, which shows the same set of three phase transitions. Thus, the EPR of $\mathrm{Fe}^{3+}$ in $\mathrm{KNbO}_{3}$ was investigated experimentally by Siegel et al. [50]. The only phase where results are available so far, is at room temperature, i.e., in the orthorhombic phase. It turned out that $a$ is essentially the same as in $\mathrm{BaTiO}_{3}$. In figure 4 measured $a$ parameters in nearcubic oxides are compared and shown to vary systematically as a function of the intrinsic lattice constant $d$ [53]. They follow a $\underline{a}=a_{0} / d^{7}$ law, irrespective of the nominal charge of the ion which the $\mathrm{Fe}^{3+}$ replaces. The anomalously low value of $\underline{a}$ in $\mathrm{BaTiO}_{3}$ and $\mathrm{KNbO}_{3}$ is striking and could be a microscopic test quantity for $\mathrm{ABO}_{3}$ ferroelectrics with Slater-type B-ion motion. The above statement is further supported by recent EPR measurements by Rytz et al. in mixed crystals, $\mathrm{KTa}_{1-x} \mathrm{Nb}_{x} \mathrm{O}_{3}[54]$ for $0 \leqslant x<0.15$. Although the lattice constant $d$ remains essentially the same, the EPR parameter $a$ decreases linearly with $x$ from the pure $\mathrm{KTaO}_{3}$ value of $0.0305 \mathrm{~cm}^{-1}$ and extrapolates to $0.010 \mathrm{~cm}^{-1}$ for pure $\mathrm{KNbO}_{3}$. It is interesting to note that the ferroelectric transition temperature increases linearly with $x$ [55].

\section{References}

[1] Mueller, K. A., Helv. Phys. Acta 31 (1958) 173.

[2] Slonczewski, J. C., Mueller, K. A. and Berlinger, W., Phys. Rev. B 1 (1970) 3545.

[3] Mueller, K. A., von WaldKIRCh, Th., in Local Properties at Phase Transitions, Proceedings of Enrico Fermi Int. School of Physics (North Holland, Amsterdam) 1976, p. 187.

[4] Hornig, A. W., Rempel, R. C. and Weaver, H. E., J. Phys. Chem. Solids 10 (1959) 1.
[5] Megaw, H. D., Crystal structures : A working approach (W. B. Saunders, London, England) 1973.

[6] Rimai, L. and De Mars, G. A., Phys. Rev. 127 (1962) 702 ; and in Proceedings of the 1st. International Conference on Paramagnetic Resonance, W. Low Ed. (Academic Press, N. Y.) 1963 , p. 51.

[7] Hannon, D. M., Phys. Rev. 164 (1967) 366.

[8] Takeda, T. and Watanabe, A., J. Phys. Soc. Japan 19 (1964) 1742 and ibid. 21 (1966) 1132. 
[9] Schirmer, O. F. and Mueller, K. A., Phys. Rev. B 7 (1973) 2986 ;

Van Engelen, P. P. J. and Henning, J. C. M., Phys. Lett. 25A (1967) 733.

[10] Graenicher, H., Huebner, K. and Mueller, K. A., Helv. Phys. Acta 30 (1957) 480.

[11] Stoneham, A. M. and SANGSTER, M. J., preprint (1980).

[12] Kool, T. W. and GlaSBeEK, M., Solid State Commun. 32 (1978) 1099.

[13] Mueller, K. A., Arch. Sci. Genève 11 (1958) 150.

[14] Mueller, K. A., Magnetic Resonance and Related Phenomena, Proceedings 16th Congress Ampère, 1971, I. Ursu Ed., (Rumanian Acad. Sci.) p. 173.

[15] Serway, R. A., Berlinger, W., Mueller, K. A. and Collins, R. W., Phys. Rev. B 16 (1977) 4761.

[16] Mueller, K. A., Phys. Rev. Lett. 2 (1959) 341.

[17] Bhide, V. G. and Bhasin, H. C., Phys. Rev. 172 (1968) 290 and references therein.

[18] Faughnan, B. W., Phys. Rev. B 4 (1971) 3623, Blazey, K. W., Phys. Status Solidi 38 (1976) K 97.

[19] Mueller, K. A., von Waldkirch, Th., Berlinger, W. and Faughnan, B. W., Solid State Commun. 9 (1971) 1097.

[20] Mueller, K. A. and Berlinger, W., unpublished.

[21] Rubins, R. S. and Low, W., Proceedings of the 1st. International Conference on Paramagnetic Resonance, W. Low Ed. (Academic Press, N. Y.) 1963, p. 59.

[22] Koidl, P., BlAzey, K. W., Berlinger, W. and Mueller, K. A., Phys. Rev. B 14 (1976) 2703.

[23] Henderson, B., Proc. Phys. Soc. London 92 (1967) 1064.

[24] Ixushima, H. and Hayakawa, S., J. Phys. Soc. Japan 27 (1969) 414 and references therein.

[25] Hannon, D. M., Phys. Rev. B 3 (1971) 2153.

[26] Siegel, E. and Mueller, K. A., Phys. Rev. B 19 (1979) 109.

[27] Sroubek, Z., Zdansky, K. and Simanek, E., Phys. Status Solidi 3 (1963) K1.

[28] Faughnan, B. W., Phys. Rev. B 5 (1972) 4925.

[29] KirkPatrick, E. S., Mueller, K. A. and Rubins, R. S., Phys. Rev. 135 (1964) A86

[30] Wessel, G. and Goldick, H., J. Appl. Phys. 39 (1968) 4855; LewIS, O. and Wessel, G., Phys. Rev. B 13 (1976) 2742.

[31] Gainon, D. J. A., J. Appl. Phys. 36 (1965) 2325.

[32] Von Waldkirch; Th., Mukller, K. A. and Berlinger, W., Phys. Rev. B 5 (1972) 4324.
[33] Hannon, D. M., Phys. Status Solidi (b) 43 (1971) K21.

[34] Faughnan, B. W., RCA Internal Reports (1969), unpublished.

[35] Berney, R. L., Cowan, D. L. and Morin, F., Solid State Commun. 26 (1978) 579. The interpretation of the $g$ values for the $\mathrm{Fe}^{1+}-\mathrm{V}_{0}$ centre can be carried out as done for $\mathrm{Co}^{2+}-\mathrm{V}_{\mathrm{O}}$ in references [33] and [34]. A detailed account including photochromic studies appeared most recently : Berney, R. L. and Cowan, D. L., Phys. Rev. B 23 (1981) 37.

[36] Mueller, K. A., Berlinger, W. and Rubins, R. S., Phys. Rev. 186 (1969) 361.

[37] Schirmer, O. F., Berlinger, W. and Mueller, K. A., Solid State Commun. 16 (1975) 1289.

[38] Morin, F. J. and Oliver, J. R., Phys. Rev. B 8 (1973) 5847.

[39] MuelLeR, K. A., Proceedings IV Ampère International Summer School on Magnetic Resonance in Condensed MatterRecent Developments, Pula, Yugoslavia (1977), Eds. R. Blinc and G. Lahajnar (Univ. of Ljubliana, Yugoslavia) p. 663 .

[40] Geifman, I. N., Phys. Status Solidi (b) 85 (1978) K5.

[41] .Takeda, T. and Watanabe, A., Japan. J. Appl. Phys. 7 (1968) 232 and references therein.

[42] Newman, D. J. and Urban, W., Adv. Phys. 24 (1975) 793; Newman, D. J. and Siegel, E., J. Phys. C : Solid State 9 (1976) 4285.

[43] Sakudo, T., J. Phys. Soc. Japan 18 (1963) 1626

[44] Sakudo, T. and Unoki, H., J. Phys. Soc. Japan 19 (1964) 2109.

[45] Jona, F. and Shirane, G., Ferroelectric Cristals (Pergamon, London) 1962, p. 249.

[46] TAKedA, T., J. Phys. Soc. Japan 24 (1968) 533.

[47] Siegel, E. and Mueller, K. A., Phys. Rev. B 20 (1979) 3587.

[48] Wemple, S. H., MIT Technical Report 425 (1962) 53.

[49] Pontin, R. G., Slade, E. F. and Ingram, D. J. E., J. Phys. C 2 (1969) 1146

[50] Siegel, E., Urban, W., Mueller, K. A. and Wiesendanger, E., Phys. Lett. 53A (1975) 415.

[51] Ihrig, H., J. Phys. C 11 (1978) 819.

[52] Hagemann, H. J. and Ihrig, H., Phys. Rev. B 20 (1979) 3871.

[53] Mueller, K. A., Phys. Rev. B 13 (1976) 3209.

[54] Rytz, D., Boatner, C. A., Chatelain, A., hoechli, U. T. and Mueller, K. A., Helv. Phys. Acta 51 (1978) 430.

[55] Triebwasser, S., Phys. Rev. 114 (1959) 63. 